\title{
Alantolactone: A Natural Plant Extract as a Potential Therapeutic Agent for Cancer
}

\author{
Yuan Cai ${ }^{1 \dagger}$, Kewa Gao ${ }^{1 \dagger}$, Bi Peng ${ }^{1}$, Zhijie Xu ${ }^{1,2,3}$, Jinwu Peng ${ }^{1,3 *}$, Juanni $\mathrm{Li}^{1}, \mathrm{Xi}_{\mathrm{Chen}}{ }^{2,4}$, \\ Shuangshuang Zeng ${ }^{2,4}$, Kuan $\mathrm{Hu}^{5}$ and Yuanliang $\mathrm{Yan}^{4}$
}

${ }^{1}$ Department of Pathology, Xiangya Hospital, Central South University, Changsha, China, ${ }^{2}$ National Clinical Research Center for Geriatric Disorders, Xiangya Hospital, Central South University, Changsha, China, ${ }^{3}$ Department of Pathology, Xiangya Changde Hospital, Changde, China, ${ }^{4}$ Department of Pharmacy, Xiangya Hospital, Central South University, Changsha, China, ${ }^{5}$ Department of Hepatobiliary Surgery, Xiangya Hospital, Central South University, Changsha, China

\section{OPEN ACCESS}

Edited by:

Peixin Dong,

Hokkaido University, Japan

Reviewed by:

Yaniie Zhao,

Qingdao University, China

Ming Li,

Fudan University, China

*Correspondence:

Jinwu Peng

jinwupeng@csu.edu.cn

${ }^{+}$These authors have contributed equally to this work

Specialty section:

This article was submitted to Pharmacology of Anti-Cancer Drugs,

a section of the journal

Frontiers in Pharmacology

Received: 22 September 2021

Accepted: 03 November 2021

Published: 26 November 2021

Citation:

Cai Y, Gao K, Peng B, Xu Z, Peng J, Li J, Chen X, Zeng S, Hu K and Yan Y (2021) Alantolactone: A Natural Plant

Extract as a Potential Therapeutic Agent for Cancer.

Front. Pharmacol. 12:781033. doi: 10.3389/fphar.2021.781033
Alantolactone (ALT) is a natural compound extracted from Chinese traditional medicine Inula helenium L. with therapeutic potential in the treatment of various diseases. Recently, in vitro and in vivo studies have indicated cytotoxic effects of ALT on various cancers, including liver cancer, colorectal cancer, breast cancer, etc. The inhibitory effects of ALT depend on several cancer-associated signaling pathways and abnormal regulatory factors in cancer cells. Moreover, emerging studies have reported several promising strategies to enhance the oral bioavailability of ALT, such as combining ALT with other herbs and using ALT-entrapped nanostructured carriers. In this review, studies on the anti-tumor roles of ALT are mainly summarized, and the underlying molecular mechanisms of ALT exerting anticancer effects on cells investigated in animal-based studies are also discussed.

Keywords: Alantolactone, anticancer effects, cancer, signaling pathways, regulatory factors

\section{INTRODUCTION}

Cancer is characterized by a very high incidence rate and fatality rate, and seriously affects human health (Fidler et al., 2017). Cancer maintains the malignancy by affecting the development of the embryo and destroying the repair mechanisms (Guan et al., 2020). It has been found that genomicsbased assays can be used in clinical therapy, such as targeted treatment and antitumor vaccines (Berger and Mardis, 2018). Currently, surgical resection, radiotherapy, and chemotherapy are the main effective modalities for curing cancers. Chemotherapy uses anti-cancer compounds and medicine to attenuate cancer development (Seo et al., 2009). However, treatment failure and side effects are common in chemotherapy. Therefore, new drugs with better therapeutic effects and fewer adverse effects are needed for cancer treatment.

Nowadays, alantolactone (ALT), a natural herb compound derived from the traditional Chinese medicinal Inula helenium L., has attracted extensive research attention because of the therapeutic potential in cancer treatment (Mi et al., 2014). It has been revealed that ALT can

Abbreviations: ALT, alantolactone; AKT, alpha serine/threonine-protein kinase; AP2M1, adaptor-related protein complex 2 subunit mu 1; EGFR, epidermal growth factor receptor; GSK, glycogen synthase kinase; HBV, hepatitis B virus; HCV, hepatitis $C$ virus; HUVEC, human umbilical vein endothelial cells; ICD, immunogenic cell death; MAPK, Mitogen-activated protein kinases; Nrf2, nuclear factor E2-related factor 2; PINK1, putative kinase 1; PLC $\gamma 1$, phospholipase C gamma 1; ROS, reactive oxygen species; STAT3, signal transducer and activator of transcription 3; TCM, traditional Chinese medicines; TrxR1, thioredoxin reductase 1; VEGFR2, vascular endothelial growth factor receptor 2. 


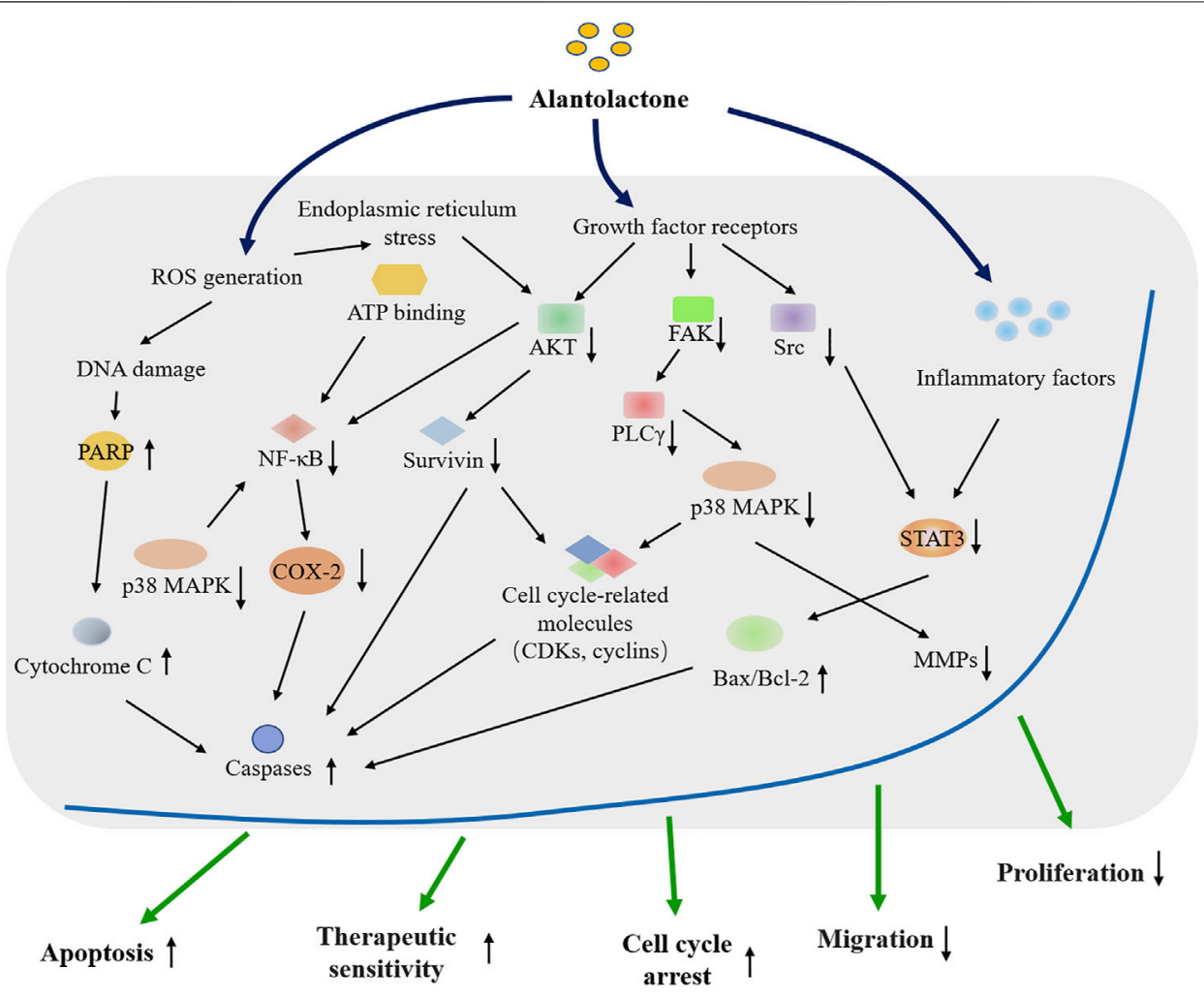

FIGURE 1 | Overview of the cytotoxic effects of the natural compound Alantolactone on cancer research and therapy.

exhibit anti-inflammatory and anti-tumor activities through modulating the abnormal signaling pathways in cancer cells (Gierlikowska et al., 2020; Babaei et al., 2021). For example, mitogen-activated protein kinases (p38 MAPK) and NF- $\mathrm{kB}$ signaling pathways are significantly attenuated by ALT, inhibiting cell viability and promoting cell apoptosis in lung cancer cell lines NCI-H1299 and Anip973 (Liu et al., 2019). And a recent study firstly reported that ALT could suppress the activation of YAP1/TAZ, leading to the inhibition of cancer cell growth (Nakatani et al., 2021). ALT could downregulate the serine/threonine kinase Aurora-A through directly binding to the interface pocket of Aurora-A-TPX2 complex, weakening several cancerassociated biological behaviors, including centrosome amplification, chromosomal instability and oncogenic transformations (Bhardwaj and Purohit, 2020; Nadda et al., 2020). Furthermore, with no obvious side effects, ALT could synergistically enhance the cytotoxic effects with other anti-cancer agents, such as oxaliplatin (Cao et al., 2019) and olaparib (Wang et al., 2020) in vivo and in vitro.

In this paper, the findings regarding the antagonistic effects of ALT in various cancers are summarized, and the underlying mechanism of ALT anticancer activity is explored (Figure 1, Tables 1, 2). Besides, to explore the practical values of ALT in future clinical applications, the safety and efficacy of ALT are also discussed.

\section{THE ACTION OF ALT AGAINST HUMAN CANCERS}

\subsection{Lung Cancer}

Lung cancer is one of the most frequent human malignancies worldwide, causing about 1.6 million deaths annually. Risk factors of lung cancer include second-hand smoking, air pollution, genetic reason, etc. ( $\mathrm{Wu}$ et al., 2020; Yang et al., 2020). In addition, non-small cell lung cancer, accounting for $\sim 85 \%$ of lung cancer cases, is increasing in both incidence and mortality. Non-small cell lung cancer is divided into two histological subtypes, namely lung adenocarcinoma and lung squamous cell carcinoma (Chen et al., 2020; Tubio-Perez et al., 2020). Nowadays, the potential therapeutic effects of traditional medicine, like ALT on patients with both subtypes of non-small cell lung cancer have been studied. It has been found that ALT effectively induces cell apoptosis in both lung squamous carcinoma cells (SK-MES-1) and lung adenocarcinoma cells (NCI-H1299 and Anip973) and the cytotoxic influence of ALT is closely related to the improved treatment efficacy and prognosis of patients with lung cancer (Zhao et al., 2015; Liu et al., 2019). It has also been found that ALT could significantly enhance the anticancer effects of chemotherapy drug gemcitabine on lung adenocarcinoma cells A549 and lung squamous carcinoma cells NCI-H520 cells through inhibiting the activation of AKT/glycogen synthase kinase (GSK) $3 \beta$ and 
TABLE 1 | The anticancer activities and the underlying mechanisms of alantolactone in vitro.

\begin{tabular}{|c|c|c|c|c|}
\hline Cancers & Cell lines & Modulated factors & Biological effects & References \\
\hline \multirow[t]{3}{*}{ Liver cancer } & HepG2 cells & Bcl-2, caspase-3, STAT3 & Inducing apoptosis, inhibiting cell & Khan et al. (2013) \\
\hline & & Bcl-2, NF-кB, p53, Bax, caspase-3/8/9, t-Bid & proliferation, inducing G2/M phase arrest & Lei et al. (2012) \\
\hline & & p21, cyclin A1 cyclin B1, caspase-3, PARP & & Kang et al. (2019) \\
\hline \multirow[t]{6}{*}{$\begin{array}{l}\text { Colorectal } \\
\text { cancer }\end{array}$} & $\begin{array}{l}\text { SW480 and SW } 1116 \text { cells, } \\
\text { non-cancer BEAS-2B and } \\
\text { L-O2 cells }\end{array}$ & Bcl-2, Bax, caspase-3, p21 & $\begin{array}{l}\text { Inducing G1 cell cycle arrest, inducing } \\
\text { apoptosis, inhibiting cell proliferation }\end{array}$ & Ding et al. (2016) \\
\hline & $\begin{array}{l}\text { Murine CT26-FL3 cells, } \\
\text { Murine breast cancer } 4 \mathrm{~T} 1 \\
\text { cells }\end{array}$ & $\mathrm{Bcl}-2, \mathrm{Bcl}-\mathrm{xL}$ & & Zhang et al. (2019a) \\
\hline & HCT116 and RKO cells & JNK, p38, MAPK, Ki-67 & & Cao et al. (2019) \\
\hline & HCT-8, L02, HEK 293 & Cripto-1, ActRIIA, activin, SMAD3, p21 & & Shi et al. (2011) \\
\hline & $\mathrm{T}$ cells & & & \\
\hline & RKO cells & MMP, Bcl-2, Bax, caspase-3/9, cytochrome c & & Zhang et al. (2013) \\
\hline \multirow[t]{5}{*}{ Breast cancer } & McF-7 cells & $\begin{array}{l}\text { Bcl-2, Bcl-2-associated X protein, p53, p65, } \\
\text { caspase-3, caspase-12, MMP-2, MMP-7, MMP-9, } \\
\text { p38, MAPK, NF-kB, Nrf2 }\end{array}$ & $\begin{array}{l}\text { Inhibiting cell proliferation, inducing } \\
\text { apoptosis, inhibiting motility, migration and } \\
\text { tube formation, causing cell cycle arrest }\end{array}$ & Liu et al. (2018a) \\
\hline & $\begin{array}{l}\text { HUVECs, MDA-MB-231 } \\
\text { cells }\end{array}$ & VEGFR2phosphorylation, PLC $\gamma 1$, FAK, Src, Akt & & Liu et al. (2018b) \\
\hline & $\begin{array}{l}\text { Triple-negative breast } \\
\text { cancer (TNBC) cells }\end{array}$ & $\begin{array}{l}\text { Bcl-2, Bax, caspase-3, CyclinB1, Cdc2, ATF4, } \\
\text { CHOP, ki-67 }\end{array}$ & & Yin et al. (2019) \\
\hline & $\begin{array}{l}\text { MDA-MB-231, MCF-7 } \\
\text { cells }\end{array}$ & $\begin{array}{l}\text { Bax/Bcl-2, MMP, cytochrome c, caspase 9/3, } \\
\text { PARP, MAPKs, p-NF-kB, p65, p-STAT3, NF- } \mathrm{B} \text {, } \\
\text { AP-1, STAT3 }\end{array}$ & & Cui et al. (2018) \\
\hline & & $\begin{array}{l}\text { STAT3, MAPKs, NF-kB, IL-6, EGFR, cyclin D1, } \\
\text { c-Rel, p65, p50, JNK/AP-1 }\end{array}$ & & Chun et al. (2015) \\
\hline \multirow[t]{4}{*}{ Lung cancer } & $\begin{array}{l}\mathrm{NCl}-\mathrm{H} 1299 \text { and Anip973 } \\
\text { cells }\end{array}$ & $\begin{array}{l}\text { Bcl-2, MMP-9, MMP-7, and MMP-2, } \beta \text {-actin, } \\
\text { p38MAPK, NF-kB }\end{array}$ & $\begin{array}{l}\text { Inducing cell apoptosis, suppressing } \\
\text { migration, invasion, and colony formation, }\end{array}$ & Liu et al. (2019) \\
\hline & SK-MES-1 cells & $\begin{array}{l}\text { Caspases-8, -9, -3, PARP, Bcl-2, Bax, CDK4, } \\
\text { CDK6, cyclin D3, cyclin D1, p21, p27 }\end{array}$ & inhibiting cell proliferation & Zhao et al. (2015) \\
\hline & $\begin{array}{l}\text { A549 cells and } \mathrm{Ncl}-\mathrm{H} 520 \\
\text { cells }\end{array}$ & $\begin{array}{l}\text { Xiap, survivin, caspase-9, caspase-3, PARP, ATF4, } \\
\text { elF2 } \alpha \text {, CHOP, Bcl-2, Bax, STAT3, iNOS, COX-2, } \\
\text { MMP-9 }\end{array}$ & & $\begin{array}{l}\text { Maryam et al. } \\
(2017)\end{array}$ \\
\hline & & PI3K/Akt, ER, p21, cyclin A2 & & Wang et al. (2019a) \\
\hline \multirow[t]{5}{*}{ Leukemia } & HL-60 cells & Cytochrome c, Bax, caspase-3, PARP & Inducing apoptosis, inhibiting cell & Pal et al. (2010) \\
\hline & THP-1 cells & $\begin{array}{l}\text { STAT-3, survivin, Bcl-2, Bcl-xL, Bax, cl-caspase-3, } \\
\text { cl-PARP, cytochrome c }\end{array}$ & proliferation, inducing cell cycle arrest & Ahmad et al. (2021) \\
\hline & $\begin{array}{l}\text { K562 and K562r cells } \\
\text { CML blast cells }\end{array}$ & NF-кB, p65 Bcr/Abl protein, caspase-3, PARP-1 & & Wei et al. (2013) \\
\hline & BV173 and NALM6 cells & $\begin{array}{l}\text { AP2M1, Beclin1, LC3-II/LC3-1, p62, Bax, cleaved } \\
\text { caspase 3, cytochrome C, Bcl-2 }\end{array}$ & & Shi et al. (2020) \\
\hline & B-ALL cell lines & $\begin{array}{l}\text { PARP-1, capase-3, caspase-8, caspase- } 9 \text {, NF-кB, } \\
\text { BCR-ABL, EGFR }\end{array}$ & & Xu et al. (2019b) \\
\hline \multirow[t]{3}{*}{$\begin{array}{l}\text { Pancreatic } \\
\text { cancer }\end{array}$} & $\begin{array}{l}\text { MIA PaCa-2 and PANC-1 } \\
\text { cells }\end{array}$ & TFEB, CTSB/CTSD & $\begin{array}{l}\text { Inducing apoptosis, improving } \\
\text { chemosensitivity, inhibiting proliferation, }\end{array}$ & He et al. (2018) \\
\hline & $\begin{array}{l}\text { BxPC-3, AsPC-1, and } \\
\text { PANC-1 cell lines }\end{array}$ & STAT3 & inhibiting migration & Zheng et al. (2019) \\
\hline & PANC-1 and SW1990 cells & Caspase 3/7, Bak, Bcl-2, Mcl-1, XIAP, STAT3 & & Yan et al. (2020) \\
\hline \multirow[t]{2}{*}{ Gastric cancer } & $\begin{array}{l}\text { SGC-7901 and BGC-823 } \\
\text { cells }\end{array}$ & $\begin{array}{l}\text { TrxR1, p38MAPK, p38, Ki-67, Bcl-2 } \\
\text { Bcl-2, Bax, cleaved PARP, cyclin D1, p21, p27, } \\
\text { AKT, cyclin-dependent kinase inhibitor 1, cyclin- } \\
\text { dependent kinase inhibitor 1B }\end{array}$ & Inhibiting proliferation, inducing apoptosis & $\begin{array}{l}\text { He et al. (2019a) } \\
\text { Zhang and Zhang } \\
\text { (2019) }\end{array}$ \\
\hline & & $\begin{array}{l}\text { Bax, Bcl-2, p53, MMP-2, MMP-7, MMP-9, NF-кB, } \\
\text { p38MAPK, p65 }\end{array}$ & & He et al. (2019b) \\
\hline \multirow[t]{3}{*}{ Cervical cancer } & HeLa cells & $\mathrm{Bcl}-2$, Bax & Inhibiting proliferation, inducing apoptosis & Jiang et al. (2016) \\
\hline & & Caspase-3, Bax, Bcl-2, NF-кB & & Zhang et al. (2019b) \\
\hline & & TrxR, caspase 3 & & Zhang et al. (2019a) \\
\hline Glioblastoma & U87 and U251 cells & $\begin{array}{l}\text { IKK } \beta / N F-\kappa B, p 50, p 65, p 300, \text { COX-2, cytochrome } \\
\text { c, cyclin D1, CDK4, MMP-2, MMP-9, caspase-3/9, } \\
\text { PARP, Bax, Bcl-2 }\end{array}$ & Inhibiting cell growth, inducing apoptosis & $\begin{array}{l}\text { Khan et al. (2012), } \\
\text { Wang et al. (2017) }\end{array}$ \\
\hline Osteosarcoma & U2OS and HOS cells & $\begin{array}{l}\text { PI3K/AKT, cyclin D1, p27, Bcl-2, Bax, cleaved } \\
\text { caspase-3/8, MMP-2, MMP-9 }\end{array}$ & Inhibiting proliferation, promoting apoptosis & Zhang et al. (2019c) \\
\hline $\begin{array}{l}\text { Multiple } \\
\text { myeloma }\end{array}$ & $\begin{array}{l}\text { RPMI8226, NCl-H929, } \\
\text { IM9, MM1R, MM1S, OPM2 }\end{array}$ & $\begin{array}{l}\text { ERK1/2, IL-6, VEGF, caspase-3/8/9, Bcl-2, Bax, } \\
\text { survivin, cyclin D, cyclin E, CDK 2, CDK 4, MAPK }\end{array}$ & $\begin{array}{l}\text { Inhibiting proliferation, inducing G1 phase } \\
\text { arrest, inducing apoptosis }\end{array}$ & Yao et al. (2015) \\
\hline
\end{tabular}
and U266 cells 
TABLE 2 | The anticancer activities and the underlying mechanisms of alantolactone in vivo.

\begin{tabular}{|c|c|c|c|c|}
\hline Cancers & Animals & Modulated factors & Biological effects & References \\
\hline \multirow[t]{2}{*}{$\begin{array}{l}\text { Colorectal } \\
\text { cancer }\end{array}$} & $\begin{array}{l}\text { Six-week-old female Balb/c } \\
\text { mice female sprague- } \\
\text { dawley rats }\end{array}$ & $\begin{array}{l}\text { HMGB1, CRT, MHCII, CD86, macrophages, MDSCs, } \\
\text { TNF- } \alpha \text {, IFN- } \gamma\end{array}$ & $\begin{array}{l}\text { Promoting antitumor response, } \\
\text { suppressing cell proliferation, inducing } \\
\text { apoptosis }\end{array}$ & Zhang et al. (2019a) \\
\hline & $\begin{array}{l}\text { Five-week-old female } \\
\text { athymic BALB/c mice }\end{array}$ & JNK, p38, MAPK, Ki-67 & & Cao et al. (2019) \\
\hline \multirow[t]{3}{*}{ Breast cancer } & $\begin{array}{l}\text { Chick embryo CAM BALB/c } \\
\text { nude mice }\end{array}$ & VEGFR2phosphorylation, PLC $\gamma 1$, FAK, Src, Akt & $\begin{array}{l}\text { Inducing apoptosis, causing cell cycle } \\
\text { arrest suppressing growth of xenograft }\end{array}$ & Liu et al. (2018b) \\
\hline & $\begin{array}{l}\text { MDA-MB-231 xenografts in } \\
\text { nude mice }\end{array}$ & $\begin{array}{l}\text { Bcl-2, Bax, caspase-3, cyclinB1, Cdc2, ATF4, CHOP, } \\
\text { ki-67 }\end{array}$ & tumors & Yin et al. (2019) \\
\hline & $\begin{array}{l}\text { Female athymic BALB/c } \\
\text { nude mice }\end{array}$ & $\begin{array}{l}\text { STAT3, MAPKs, NF-кB, IL-6, EGFR, cyclin D1, c-Rel, } \\
\text { p65, p50, JNK/AP-1 }\end{array}$ & & Chun et al. (2015) \\
\hline \multirow[t]{2}{*}{ Leukemia } & $\begin{array}{l}\text { BV173 xenograft nude } \\
\text { mouse model }\end{array}$ & $\begin{array}{l}\text { AP2M1, Beclin1, LC3-II/LC3-1, p62, Bax, cleaved } \\
\text { caspase 3, cytochrome C, Bcl-2 }\end{array}$ & $\begin{array}{l}\text { Inhibiting cell proliferation, inducing } \\
\text { apoptosis, inducing cell cycle arrest }\end{array}$ & Shi et al. (2020) \\
\hline & $\begin{array}{l}\text { B-ALL mice model (NOD- } \\
\text { SCID mice) }\end{array}$ & $\begin{array}{l}\text { PARP-1, capase-3, caspase-8, caspase- } 9 \text {, NF- } к B, \text { BCR- } \\
\text { ABL, EGFR }\end{array}$ & & Xu et al. (2019b) \\
\hline Pancreatic & Female nude BALB/c mice & TFEB, CTSB/CTSD & Inducing apoptosis, improving & He et al. (2018) \\
\hline cancer & $\begin{array}{l}\text { Female Wild-type BALB/c } \\
\text { mice }\end{array}$ & STAT3 & chemosensitivity & Zheng et al. (2019) \\
\hline Gastric cancer & $\begin{array}{l}\text { Athymic BALB/c nu/nu } \\
\text { female mice }\end{array}$ & TrxR1, p38MAPK, p38, Ki-67, Bcl-2 & $\begin{array}{l}\text { Inhibiting proliferation, inducing } \\
\text { apoptosis }\end{array}$ & He et al. (2019a) \\
\hline Glioblastoma & $\begin{array}{l}\text { BALB/c nu/nu male nude } \\
\text { mice }\end{array}$ & $\begin{array}{l}\text { IKK } \beta / N F-\kappa B, p 50, p 65 \text {, p300, COX-2, cytochrome c, } \\
\text { cyclin D1, CDK4, MMP-2, MMP-9, caspase-3/9, PARP, } \\
\text { Bax, Bcl-2 }\end{array}$ & $\begin{array}{l}\text { Inhibiting cell growth, inducing } \\
\text { apoptosis }\end{array}$ & $\begin{array}{l}\text { Khan et al. (2012), } \\
\text { Wang et al. (2017) }\end{array}$ \\
\hline
\end{tabular}

endoplasmic reticulum (ER) stress pathways (Wang J. et al., 2019). After treatment on A549 lung adenocarcinoma cells, ALT performs the biological functions to trigger oxidative stress mediated-cell apoptosis by abrogating the glutathionylation-dependent STAT3 activation (Maryam et al., 2017). The above studies show the molecular mechanism and biological significance of ALT in the treatment of lung cancer.

\subsection{Liver Cancer}

Liver cancer, with a high death rate and poor 5-years survival, is considered to be one of the most malignant cancers in the world (Feng et al., 2020). The factors leading to liver cancer are as follows: infection of hepatitis B virus (HBV), infection of hepatitis $\mathrm{C}$ virus $(\mathrm{HCV})$, alcohol abuse, and alternations of genetic and epigenetic events (Zhang et al., 2020b). There are many strategies to treat liver cancer, such as chemotherapy, radiotherapy, molecular targeted therapy, surgical resection, and liver transplantation (Petrowsky et al., 2020). However, the prognosis is unsatisfactory because of the complex risks and pathological factors (Zhang et al., 2020a; Ruan et al., 2020). Therefore, a new treatment is needed. A recent study has explored the mechanism of ALT-mediated apoptosis in liver cancer cells HepG2 and found that through down-regulating reactive oxygen species (ROS)-mediated alpha serine/threonineprotein kinase (AKT) activation and weakening PTEN induced putative kinase 1 (PINK1)-mediated cell mitophagy, ALT treatment could induce apoptosis in HepG2 cells (Kang et al., 2019). It has also been shown that mitochondrial membrane in HepG2 cells loses the potential when being exposed to ALT and ALT induces apoptosis through modulating the levels of several apoptosis-associated proteins, including Bax, Bak, caspases, etc. (Lei et al., 2012). Another study has drawn a similar conclusion that ALT treatment could enhance $\mathrm{Bax} / \mathrm{Bcl}-2$ ratio, promote caspase- 3 activation and elevate ROS generation, contributing to inducing apoptosis of HepG2 cells. The abnormally over-expressed and activated signal transducer and activator of transcription 3 (STAT3) signaling pathway have also been proved to be impaired by ALT in liver cancer cells (Khan et al., 2013). These studies indicate that ALT has the potential to be a leading chemotherapeutic candidate in the treatment of liver cancer.

\subsection{Colorectal Cancer}

At present, colorectal cancer ranks as the fourth most deadly cancer in the world. The incidence and mortality of colorectal cancer are much higher in developing countries than in developed countries because of the differences in medical service quality (Suliman et al., 2019; Almatroudi, 2020). It has been found that the incidence of colorectal cancer has a younger trend (The Lancet, 2017; The Lancet Gastroenterology, 2018). Colorectal cancer is a heterogeneous disease with many molecular subtypes, which is beneficial to the prognosis and immunotherapy of cancer (Becht et al., 2016; Wirth and Schneider, 2016). Nowadays, many traditional Chinese medicines (TCM) have been applied to the clinical therapy of cancers. Quercetin synergized with ALT could significantly induce immunogenic cell death (ICD) in colorectal cancer cells. This synergistic therapeutic effect is capable of reversing the immune-suppressive tumor microenvironment, thereby improving cell toxicity and antitumor immunity (Zhang J. et al., 2019). Ding et al. have explored the underlying molecular mechanism of ALT in human colorectal cancer cells SW480 and SW1116 and found that after ALT treatment, the accumulation of ROS causes oxidative DNA damage, contributing to the intrinsic apoptosis pathway of cancer cells (Ding et al., 2016). In addition to causing oxidative DNA damage, 
ALT could strengthen the effects of oxaliplatin in HCT116 and RKO cells by inducing the activation of MAPK-JNK/c-Jun pathway, deactivation of the JNK pathway, inhibition of p38 MAPK pathway and decrease of intracellular ROS, as has been suggested by two independent studies. The two studies suggest that ALT could suppress cell proliferation and exhibit anticancer effects on colorectal cancer HCT-8 cells and HCT-116 cells (Shi et al., 2011; Babaei et al., 2021; Ren et al., 2021). Besides, ALT could exert the dose-dependently cytotoxic effects on RKO human colon cancer cells and induce cell apoptosis through modulating ROS-mediated mitochondria-dependent pathway (Zhang et al., 2013). The above studies show that ALT treatment could be clinically applied for patients with colorectal cancer in the future.

\subsection{Breast Cancer}

Breast cancer is a common cancer in women (Liu Y. et al., 2020; Wan et al., 2020). Although the diagnosis strategies like the mammogram, have been developed in recent years, the mortality rate of breast cancer is still high (Ranjkesh et al., 2020; Xu et al., 2020). As a result, innovative alternatives are needed to improve the therapeutic outcome of patients with breast cancer Studies have shown that ALT changes the cell morphology and decreases the cell viability of MDA-MB-231 and MCF-7 breast cancer cells (Liu J. et al., 2018; Cui et al., 2018). Administration of ALT can promote apoptosis and suppress migration of MCF-7 cells, which may be due to the decrease of p38 MAPK, NF- $\mathrm{kB}$ and nuclear factor E2-related factor 2 (Nrf2) signaling pathways (Liu J. et al., 2018). Liu et al. have revealed that ALT treatment is effective in inhibiting the motility, migration, and tube formation of human umbilical vein endothelial cells (HUVEC), which promote tumor angiogenesis. Besides, ALT impairs the angiogenesis and tumor growth by down-regulating vascular endothelial growth factor receptor 2 (VEGFR2) phosphorylation level and its downstream protein kinases, including phospholipase $\mathrm{C}$ gamma 1 (PLC $\gamma 1$ ), protein tyrosine kinase 2 (FAK), SRC, and AKT (Liu Y. R. et al., 2018). Triple-negative breast cancer is one of the most challenging subtypes of breast cancers with a high probability of relapse, distant metastasis, and poor survival (Kim et al., 2018; Garrido-Castro et al., 2019). Therefore, analyzing the correlation of ALT and the anti-tumor potential in TNBC is potentially important. Yin et al. have shown that ALT promotes cell death and inhibits cell proliferation of triplenegative breast cancer cells by inducing ROS generation and subsequent ROS-dependent ER stress. Further analyses have shown that thioredoxin reductase 1 (TrxR1) expression and activity are weakened by ALT (Yin et al., 2019). Furthermore, other studies have demonstrated that ALT, serving as a STAT3 inhibitor, suppresses cell migration and the growth of triplenegative breast cancer cells both in vitro and in vivo (Chun et al., 2015; Kim et al., 2017), highlighting the therapeutic potential in breast cancer treatment.

\subsection{Leukemia}

Leukemia is a malignant progressive disease characterized by abnormal proliferation of haemopoietic stem cells (Abdellateif et al., 2020) and can be divided into four subtypes, namely acute myeloid leukemia, acute lymphoblastic leukemia, chronical myeloid leukemia, and chronical lymphoblastic leukemia. Chronical lymphoblastic leukemia is the most common one that occurs in adults (Hallek et al., 2018; Bosch and Dalla-Favera, 2019), whereas acute lymphoblastic leukemia is most commonly observed in children (Nordlund and Syvanen, 2018). Recently, the biological activities of ALT against THP-1 leukemia cells have been investigated and the results show that ALT plays an important role in inhibiting cell viability and inducing mitochondrial apoptosis in THP-1 cells by provoking ROS production and interfering in STAT3, survivin, c-Jun, and p38 MAPK signaling pathways (Ahmad et al., 2021). Shi et al. have also demonstrated that ALT could promote the expression level of adaptor-related protein complex 2 subunit mu 1 (AP2M1) and inhibit cell proliferation, colony formation, and autophagy of acute lymphoblastic leukemia cells in a dose-dependent manner through up-regulating AP2M1 signaling (Shi et al., 2020). Moreover, the n-hexane fraction extracted from Inula racemosa Hook. f., a mixture of active ingredients mainly consisted of ALT, displays an inhibitory effect on leukemia HL-60 cells through enhancing the intrinsic and extrinsic apoptosis pathways without side effects to normal cells (Pal et al., 2010). ALT also induces cytotoxicity on B cell acute lymphoblastic leukemia in vivo and in vitro by prompting ROS overload and subsequently resulting in ROS-mediated DNA damage (Xu X. et al., 2019). After the evaluation about the potential activity of ALT in imatinib-sensitive and -resistant cells, Wei et al. have concluded that ALT treatment contributes to significant cell apoptosis in both imatinib-sensitive and -resistant leukemia cells, as indicated by the increase of caspases activation and poly (ADPribose) polymerase-1 (PARP-1) cleavage (Wei et al., 2013). These studies strongly support the application of ALT in leukemia treatment.

\subsection{Pancreatic Cancer}

Pancreatic cancer is the second leading cause of cancer death in Western countries, especially in the United States (Neoptolemos et al., 2018; Collisson et al., 2019). The treatment of pancreatic cancer is not easy as early diagnosis is hard (Moore and Donahue, 2019) and there are few effective clinical treatment approaches (Halbrook and Lyssiotis, 2017). It has been revealed that the bioactive mixture of ALT and the analogues (allo-ALT and isoALT) could exert significant anti-proliferation and antimigration effects on PANC-1 and SW1990 pancreatic cancer cells (Yan et al., 2020). It has also been shown that the combination of ALT and other treatments could exert synergized cytotoxic effects on pancreatic cancer. For example, when combined with the chemotherapy drug oxaliplatin, ALT might play a crucial role in deducing tumor-killing effects on pancreatic cancer cells through blocking cathepsin B/cathepsin D activation (He et al., 2018). Similarly, Wang et al. have revealed that ALT triggers synergistic lethality with simultaneous PARP-1 inhibition in homologous recombination-proficient cancer cells (Wang et al., 2020), and promotes the therapeutic sensitivity of pancreatic cancer cells to the anti-cancer drugs, including oxaliplatin (He et al., 2018), PARP inhibitor (olaparib) (Wang et al., 2020), epidermal growth factor receptor (EGFR) inhibitors (erlotinib and afatinib) (Zheng et al., 2019), and so on. Therefore, 
the combination of natural compound ALT and specific anticancer agents is a safe and effective strategy for pancreatic cancer treatment.

\subsection{Other Tumors}

Many studies have suggested that ALT could also exhibit cytotoxic effects on other types of cancers. It has been shown that ALT induces apoptosis and triggers cell-cycle arrest in gastric cancer cells through ROS generation and modulation of several ROS-dependent kinase signaling pathways, such as AKT, p38 MAPK, and NF-кB (He W. et al., 2019; He Y. et al., 2019; Zhang and Zhang, 2019). Furthermore, combined treatment of ALT and ferroptosis inducer erastin could exert a synergistic effect on inducing the death of gastric cancer cells (He W. et al., 2019). It has also been demonstrated that ALT exerts concentrationdependent effects on inhibiting proliferation and inducing apoptosis of cervical cancer cells through regulating the Bcl-2/ Bax radio, NF- $\kappa \mathrm{B}$ pathway, and thioredoxin reductase (TrxR) activation (Zhang J. et al., 2016; Jiang et al., 2016; Zhang Y. et al., 2019). Furthermore, a newly study have reported that ALT could inhibit the progression of HeLa cells via suppressing the expression of BMI1(Sun et al., 2021). Through downregulating the $\mathrm{NF}-\kappa \mathrm{B} / \mathrm{COX}-2$-mediated signaling cascades or triggering the cofilin/G-actin signaling, ALT inhibits the growth and induces apoptosis of glioblastoma cells both in vivo and in vitro (Khan et al., 2012; Wang et al., 2017; Wang X. et al., 2021). The similar tumor-inhibition effects of ALT, accompanied by apoptosis promotion and growth depression, could also be observed in osteosarcoma (Zhang Y. et al., 2020), esophageal cancer (Wang Z. et al., 2021), multiple myeloma (Yao et al., 2015), etc. The above studies explore the underlying molecular mechanism of the biological activity of ALT, contributing to the application of ALT as a promising chemotherapeutic candidate for different kinds of cancers.

\section{CLINICAL PERSPECTIVE OF ALT}

As an important sesquiterpenoid extracted from a frequently utilized traditional herbal medicine, ALT has been confirmed to possess a broad spectrum of pharmacological properties, including anti-tumor, anti-fungal, and anti-inflammatory activities. Up to now, many studies have reported the anticancer effects of ALT in vitro and in vivo. However, the biological actions of ALT are easily influenced by some factors, like bioavailability.

Recently, a pharmacokinetics study has suggested that the oral bioavailability of ALT is quite low, which is one challenge in clinical trial design to explore the biological actions. Some defects of ALT, such as low water solubility, limit the absorption and bioavailability in vivo (Xu et al., 2015). Low oral bioavailability probably results from intestinal metabolism, poor permeability, and low aqueous solubility (Zhou et al., 2018). However, according to the compatibility principle in the Prescription Dictionary of Chinese Medicine, the combination of ALT and other herbs could effectively reduce the toxicity and enhance intestinal absorption, contributing to stronger bioavailability and therapeutic actions (Xu R. et al., 2019). It is well known that evaluation of intestinal bacteria is one challenge in clarifying the metabolism of oral drugs (Zimmermann et al., 2019). A biotransformation strategy based on the anaerobic culture of intestinal bacteria has been developed by Yao et al. for identifying ALT metabolites (Yao et al., 2016). In addition, ALT-entrapped nanostructured carriers have been developed to improve the bioavailability and potential cytotoxicity efficacy of ALT against cancers (Zhang J. et al., 2019). These studies are beneficial for the evaluations of ALT application in the future. Unfortunately, until now, there are no clinical trials to explore the bioavailability and anti-tumor effect of ALT in cancer patients. Therefore, to verify the pharmacological activities of ALT, more investigations, especially well-designed clinical trials, remain to be determined in the future.

\section{IMPLICATION OF ALT FOR CANCER-ASSOCIATED SIGNALING PATHWAYS}

As shown in previous studies, ALT has good clinical prospects as therapeutic agents for human cancers. It has been found that ALT exerts high cytotoxicity effects, such as anti-proliferation, antimetastasis, and pro-apoptotic cascades on many human cancer cell lines through interfering with several molecular events (Zhang J. P. et al., 2016; Nadda et al., 2020).

Previous studies have illustrated the important roles of ROS in maintaining the stable microenvironment of tissues and affecting the genesis and development of malignant tumors (Ippolito et al., 2020; Shen et al., 2020). If the ROS production is not in balance, the extensive damage response in cells caused by oxidative stress would result in higher risks of diseases, like diabetes, cardiovascular disease, cancers, etc. (Tavares and Seca, 2019). Therefore, keeping the balance of ROS levels is beneficial for regulating cancer treatment efficacy (Jiang et al., 2019; Zhou et al., 2020). It has been found that ALT could increase the concentration of ROS and trigger the intrinsic apoptosis pathway of colorectal cancer cells (Ding et al., 2016). Kang et al. have reported that ALT could induce cell-cycle arrest and cell apoptosis in HepG2 cells by regulating intracellular ROS accumulation, which provides a new strategy to treat liver cancer (Kang et al., 2019).

In addition, as a transcription factor, NF- $\kappa \mathrm{B}$ is related to the regulation of carcinogens, such as promoting cell proliferation, regulating apoptosis, facilitating angiogenesis, and stimulating metastasis (Liu Z. et al., 2020; Espinosa-Sanchez et al., 2020). NF$\kappa \mathrm{B}$ also modulates the immune and inflammatory responses, influencing cancer cell growth (Fusella et al., 2017; Taniguchi and Karin, 2018). Effective regulation of the activation of the NF- $\kappa B$ signaling pathway is significant in developing chemotherapies. It has been found that ALT-targeted NF- $\mathrm{BB}$ and the downstream signaling pathways inhibit the migration of breast cancer cells and trigger the apoptosis of chronical myeloid leukemia cells (Wei et al., 2013; Liu J. et al., 2018). It has also been demonstrated that ALT promotes cell apoptosis in acute lymphoblastic leukemia and gastric cancer through inhibiting NF- $\kappa \mathrm{B}$ activation $(\mathrm{He} \mathrm{Y}$. 
et al., 2019; Xu X. et al., 2019). Besides, ALT significantly delays the cell proliferation of HeLa cells in a dose-dependent manner through targeting NF-kB signaling pathways (Zhang Y. et al., 2019).

It is well-known that clarifying the underlying functions of VEGFR contributes to the understanding of the angiogenesis and therapeutic response of cancer cells (Haibe et al., 2020; Kratzsch et al., 2020). Furthermore, VEGF plays a crucial role in the development of molecular-targeted treatment or other novel anti-cancer drugs in clinical practice (Apte et al., 2019). Liu et al. have uncovered that ALT inhibits VEGFR2 phosphorylation, and impairs VEGF-VEGFR2 signaling in HUVECs (Liu Y. R. et al., 2018). ALT could also reduce VEGF secretion, thereby suppressing the adhesion of multiple myeloma cells (Yao et al., 2015). These findings suggest that ALT may be a promising agent to fight against angiogenesis and invasion in cancers through intervening in VEGF-VEGFR pathways.

The aberrant activation of the p38 MAPK signaling pathway is involved in various biological processes, facilitating the development and treatment of cancer (Wang K. et al., 2019; Reger de Moura et al., 2020). As an essential regulating factor, p38 MAPK participates in many cellular activities, making cancer cells perceive and adapt to environmental stress signals (Low and Zhang, 2016; Martinez-Limon et al., 2020). Studies have shown that deactivating the p38 MAPK pathway could facilitate the ALT-mediated cell apoptosis in colon cancer cells and breast cancer cells (Liu J. et al., 2018; Cao et al., 2019). Moreover, ALT exerts attractive pharmacological activities on lung cancer cells by blocking the p38 MAPK pathway (He W. et al., 2019; Liu et al., 2019). He et al. have further revealed that ALT modulates the ROS-mediated p38 MAPK pathway and induces cell apoptosis in gastric cancer. More importantly, ALT treatment markedly enhances the cell sensitivity to the ferroptosis inducer erastin (He W. et al., 2019).

In addition, there are a few studies concerning about the correlation between ALT administration and cell autophagy in cancer cells. ALT could play a significant role in promoting impaired autophagy, facilitating to allay osteoarthritis and strengthen pancreatic cancer cells' chemosensitivity ( $\mathrm{He}$ et al., 2018; Pei et al., 2021). Another two studies have demonstrated that treatment with ALT could significantly downregulate the cell autophagy in ALL and liver cancer cells, implying that ALT have the potential to kill cancer cells through modulating autophagy (Kang et al., 2019; Shi et al., 2020).

Taken together, accumulating reports have showed that ALT exerts anticancer effects on various kinds of cancers, such as liver cancer, colorectal cancer, breast cancer, etc. And the potential molecular mechanisms involved in ALT's anticancer activities are

\section{REFERENCES}

Abdellateif, M. S., Kassem, A. B., and El-Meligui, Y. M. (2020). Combined Expression of CD34 and FLT3-Internal Tandem Duplication Mutation Predicts Poor Response to Treatment in Acute Myeloid Leukemia. Int. J. Gen. Med. 13, 867-879. doi:10.2147/IJGM.S276138 inhibiting JNK and p38 MAPK pathways, PI3K/AKT/GSK3 $\beta$ pathways, NF- $\kappa \mathrm{B} / \mathrm{COX}-2$ pathways and promoting cell apoptosis-associated signalings. These findings abovementioned demonstrate that ALT may be a potent therapeutic candidate for cancer reseach and treatment. However, more comprehensive studies are still needed to further explore the detailed functions of ALT.

\section{CONCLUSION}

In summary, the exploration of agents from plants will help to develop new therapeutic strategies and drugs in future clinical treatment. ALT possesses superior anti-tumor properties besides anti-inflammatory and antimicrobial activities and can be a potential drug candidate for cancer therapy. From some experiments of ALT in vivo and in vitro, we can know that ALT can synergize with chemical drugs to enhance their anticancer effects, such as Quercetin and oxaliplatin. Additionally, it was reported that ALT could enhanced the therapeutic sensitivity on cancer treatment. Although there are some studies concerning the cytotoxic effects of ALT in vivo and in vitro, more profound investigations are still needed to clarify the underlying mechanisms of ALT in the treatment of human malignancies. Besides, accurate and reliable clinical research, for example, randomized controlled trials, are needed to prove the effectiveness of ALT as a therapeutic agent for cancers.

\section{AUTHOR CONTRIBUTIONS}

YC, JP and KG: Conceptualization, Data curation, Methodology, Writing-Original draft preparation. BP: Visualization, Investigation. JL: Supervision, Resources. XC and YY: Formal analysis, Funding acquisition. SZ and KH: Software, Validation. JP, ZX and YY: Writing- Reviewing and Editing.

\section{FUNDING}

This study is supported by grants from the China Postdoctoral Science Foundation (2021T140754, 2020M672521), the National Natural Science Foundation of China (81803035), the Natural Science Foundation of Hunan Province (2020JJ5934, 2019JJ50932), and the Postdoctoral Science Foundation of Central South University (248485). We thank the Language Editing Service of KetengEdit for assistance with the language editing.

Ahmad, B., Gamallat, Y., Su, P., Husain, A., Rehman, A. U., Zaky, M. Y., et al. (2021). Alantolactone Induces Apoptosis in THP-1 Cells through STAT3, Survivin Inhibition, and Intrinsic Apoptosis Pathway. Chem. Biol. Drug Des. 97 (2), 266-272. doi:10.1111/cbdd.13778

Almatroudi, A. (2020). The Incidence Rate of Colorectal Cancer in Saudi Arabia: An Observational Descriptive Epidemiological Analysis. Int. J. Gen. Med. 13, 977-990. doi:10.2147/IJGM.S277272 
Apte, R. S., Chen, D. S., and Ferrara, N. (2019). VEGF in Signaling and Disease: Beyond Discovery and Development. Cell 176 (6), 1248-1264. doi:10.1016/ j.cell.2019.01.021

Babaei, G., Gholizadeh-Ghaleh Aziz, S., Rajabi Bazl, M., and Khadem Ansari, M. H. (2021). A Comprehensive Review of Anticancer Mechanisms of Action of Alantolactone. Biomed. Pharmacother. 136, 111231. doi:10.1016/ j.biopha.2021.111231

Becht, E., de Reyniès, A., Giraldo, N. A., Pilati, C., Buttard, B., Lacroix, L., et al. (2016). Immune and Stromal Classification of Colorectal Cancer Is Associated with Molecular Subtypes and Relevant for Precision Immunotherapy. Clin. Cancer Res. 22 (16), 4057-4066. doi:10.1158/10780432.CCR-15-2879

Berger, M. F., and Mardis, E. R. (2018). The Emerging Clinical Relevance of Genomics in Cancer Medicine. Nat. Rev. Clin. Oncol. 15 (6), 353-365. doi:10.1038/s41571-018-0002-6

Bhardwaj, V. K., and Purohit, R. (2020). Targeting the Protein-Protein Interface Pocket of Aurora-A-TPX2 Complex: Rational Drug Design and Validation. J. Biomol. Struct. Dyn. 39, 1-10. doi:10.1080/07391102.2020.1772109

Bosch, F., and Dalla-Favera, R. (2019). Chronic Lymphocytic Leukaemia: from Genetics to Treatment. Nat. Rev. Clin. Oncol. 16 (11), 684-701. doi:10.1038/ s41571-019-0239-8

Cao, P., Xia, Y., He, W., Zhang, T., Hong, L., Zheng, P., et al. (2019). Enhancement of Oxaliplatin-Induced colon Cancer Cell Apoptosis by Alantolactone, a Natural Product Inducer of ROS. Int. J. Biol. Sci. 15 (8), 1676-1684. doi:10.7150/ijbs. 35265

Chen, B., Yang, L., Zhang, R., Luo, W., and Li, W. (2020). Radiomics: an Overview in Lung Cancer Management-A Narrative Review. Ann. Transl Med. 8 (18), 1191. doi: $10.21037 / \mathrm{atm}-20-4589$

Chun, J., Li, R. J., Cheng, M. S., and Kim, Y. S. (2015). Alantolactone Selectively Suppresses STAT3 Activation and Exhibits Potent Anticancer Activity in MDA-MB-231 Cells. Cancer Lett. 357 (1), 393-403. doi:10.1016/ j.canlet.2014.11.049

Collisson, E. A., Bailey, P., Chang, D. K., and Biankin, A. V. (2019). Molecular Subtypes of Pancreatic Cancer. Nat. Rev. Gastroenterol. Hepatol. 16 (4), 207-220. doi:10.1038/s41575-019-0109-y

Cui, L., Bu, W., Song, J., Feng, L., Xu, T., Liu, D., et al. (2018). Apoptosis Induction by Alantolactone in Breast Cancer MDA-MB-231 Cells through Reactive Oxygen Species-Mediated Mitochondrion-dependent Pathway. Arch. Pharm. Res. 41 (3), 299-313. doi:10.1007/s12272-017-0990-2

Ding, Y., Wang, H., Niu, J., Luo, M., Gou, Y., Miao, L., et al. (2016). Induction of ROS Overload by Alantolactone Prompts Oxidative DNA Damage and Apoptosis in Colorectal Cancer Cells. Int. J. Mol. Sci. 17 (4), 558. doi:10.3390/ijms17040558

Espinosa-Sánchez, A., Suárez-Martínez, E., Sánchez-Díaz, L., and Carnero, A. (2020). Therapeutic Targeting of Signaling Pathways Related to Cancer Stemness. Front. Oncol. 10, 1533. doi:10.3389/fonc.2020.01533

Feng, D., Wang, M., Hu, J., Li, S., Zhao, S., Li, H., et al. (2020). Prognostic Value of the Albumin-Bilirubin Grade in Patients with Hepatocellular Carcinoma and Other Liver Diseases. Ann. Transl Med. 8 (8), 553. doi:10.21037/ atm.2020.02.116

Fidler, M. M., Gupta, S., Soerjomataram, I., Ferlay, J., Steliarova-Foucher, E., and Bray, F. (2017). Cancer Incidence and Mortality Among Young Adults Aged 20-39 Years Worldwide in 2012: a Population-Based Study. Lancet Oncol. 18 (12), 1579-1589. doi:10.1016/S1470-2045(17)30677-0

Fusella, F., Seclì, L., Busso, E., Krepelova, A., Moiso, E., Rocca, S., et al. (2017). The IKK/NF- $\kappa B$ Signaling pathway Requires Morgana to Drive Breast Cancer Metastasis. Nat. Commun. 8 (1), 1636. doi:10.1038/s41467-017-01829-1

Garrido-Castro, A. C., Lin, N. U., and Polyak, K. (2019). Insights into Molecular Classifications of Triple-Negative Breast Cancer: Improving Patient Selection for Treatment. Cancer Discov. 9 (2), 176-198. doi:10.1158/2159-8290.CD-181177

Gierlikowska, B., Gierlikowski, W., and Demkow, U. (2020). Alantolactone Enhances the Phagocytic Properties of Human Macrophages and Modulates Their Proinflammatory Functions. Front. Pharmacol. 11, 1339. doi:10.3389/ fphar.2020.01339

Guan, Y., Wang, G., Fails, D., Nagarajan, P., and Ge, Y. (2020). Unraveling Cancer Lineage Drivers in Squamous Cell Carcinomas. Pharmacol. Ther. 206, 107448. doi:10.1016/j.pharmthera.2019.107448
Haibe, Y., Kreidieh, M., El Hajj, H., Khalifeh, I., Mukherji, D., Temraz, S., et al. (2020). Resistance Mechanisms to Anti-angiogenic Therapies in Cancer. Front. Oncol. 10, 221. doi:10.3389/fonc.2020.00221

Halbrook, C. J., and Lyssiotis, C. A. (2017). Employing Metabolism to Improve the Diagnosis and Treatment of Pancreatic Cancer. Cancer Cell 31 (1), 5-19. doi:10.1016/j.ccell.2016.12.006

Hallek, M., Shanafelt, T. D., and Eichhorst, B. (2018). Chronic Lymphocytic Leukaemia. Lancet 391 (10129), 1524-1537. doi:10.1016/S0140-6736(18) 30422-7

He, R., Shi, X., Zhou, M., Zhao, Y., Pan, S., Zhao, C., et al. (2018). Alantolactone Induces Apoptosis and Improves Chemosensitivity of Pancreatic Cancer Cells by Impairment of Autophagy-Lysosome Pathway via Targeting TFEB. Toxicol. Appl. Pharmacol. 356, 159-171. doi:10.1016/j.taap.2018.08.003

He, W., Cao, P., Xia, Y., Hong, L., Zhang, T., Shen, X., et al. (2019a). Potent Inhibition of Gastric Cancer Cells by a Natural Compound via Inhibiting TrxR1 Activity and Activating ROS-Mediated P38 MAPK Pathway. Free Radic. Res. 53 (1), 104-114. doi:10.1080/10715762.2018.1558448

He, Y., Cao, X., Kong, Y., Wang, S., Xia, Y., Bi, R., et al. (2019b). Apoptosispromoting and Migration-Suppressing Effect of Alantolactone on Gastric Cancer Cell Lines BGC-823 and SGC-7901 via Regulating p38MAPK and NF-Kb Pathways. Hum. Exp. Toxicol. 38 (10), 1132-1144. doi:10.1177/ 0960327119855128

Ippolito, L., Giannoni, E., Chiarugi, P., and Parri, M. (2020). Mitochondrial Redox Hubs as Promising Targets for Anticancer Therapy. Front. Oncol. 10, 256. doi:10.3389/fonc.2020.00256

Jiang, H., Zhang, X. W., Liao, Q. L., Wu, W. T., Liu, Y. L., and Huang, W. H. (2019). Electrochemical Monitoring of Paclitaxel-Induced ROS Release from Mitochondria inside Single Cells. Small 15 (48), e1901787. doi:10.1002/ smll.201901787

Jiang, Y., Xu, H., and Wang, J. (2016). Alantolactone Induces Apoptosis of Human Cervical Cancer Cells via Reactive Oxygen Species Generation, Glutathione Depletion and Inhibition of the Bcl-2/Bax Signaling Pathway. Oncol. Lett. 11 (6), 4203-4207. doi:10.3892/ol.2016.4511

Kang, X., Wang, H., Li, Y., Xiao, Y., Zhao, L., Zhang, T., et al. (2019). Alantolactone Induces Apoptosis through ROS-Mediated AKT Pathway and Inhibition of PINK1-Mediated Mitophagy in Human HepG2 Cells. Artif. Cell Nanomed Biotechnol 47 (1), 1961-1970. doi:10.1080/21691401.2019.1593854

Khan, M., Li, T., Ahmad Khan, M. K., Rasul, A., Nawaz, F., Sun, M., et al. (2013). Alantolactone Induces Apoptosis in HepG2 Cells through GSH Depletion, Inhibition of STAT3 Activation, and Mitochondrial Dysfunction. Biomed. Res. Int. 2013, 719858. doi:10.1155/2013/719858

Khan, M., Yi, F., Rasul, A., Li, T., Wang, N., Gao, H., et al. (2012). Alantolactone Induces Apoptosis in Glioblastoma Cells via GSH Depletion, ROS Generation, and Mitochondrial Dysfunction. IUBMB Life 64 (9), 783-794. doi:10.1002/ iub. 1068

Kim, C., Gao, R., Sei, E., Brandt, R., Hartman, J., Hatschek, T., et al. (2018). Chemoresistance Evolution in Triple-Negative Breast Cancer Delineated by Single-Cell Sequencing. Cell 173 (4), 879-e13. doi:10.1016/ j.cell.2018.03.041

Kim, M., Song, K., and Kim, Y. S. (2017). Alantolactone Improves Prolonged Exposure of Interleukin-6-Induced Skeletal Muscle Inflammation Associated Glucose Intolerance and Insulin Resistance. Front. Pharmacol. 8, 405. doi:10.3389/fphar.2017.00405

Kratzsch, T., Piffko, A., Broggini, T., Czabanka, M., and Vajkoczy, P. (2020). Role of mTOR and VEGFR Inhibition in Prevention of Metastatic Tumor Growth in the Spine. Front. Oncol. 10, 174. doi:10.3389/fonc.2020.00174

Lei, J. C., Yu, J. Q., Yin, Y., Liu, Y. W., and Zou, G. L. (2012). Alantolactone Induces Activation of Apoptosis in Human Hepatoma Cells. Food Chem. Toxicol. 50 (9), 3313-3319. doi:10.1016/j.fct.2012.06.014

Liu, J., Liu, M., Wang, S., He, Y., Huo, Y., Yang, Z., et al. (2018a). Alantolactone Induces Apoptosis and Suppresses Migration in MCF-7 Human Breast Cancer Cells via the $\mathrm{p} 38$ MAPK, NF- $\mathrm{kB}$ and Nrf2 Signaling Pathways. Int. J. Mol. Med. 42 (4), 1847-1856. doi:10.3892/ijmm.2018.3751

Liu, J., Yang, Z., Kong, Y., He, Y., Xu, Y., and Cao, X. (2019). Antitumor Activity of Alantolactone in Lung Cancer Cell Lines NCI-H1299 and Anip973. J. Food Biochem. 43 (9), e12972. doi:10.1111/jfbc.12972

Liu, Y., Zhang, Q., Wu, J., Zhang, H., Li, X., Zheng, Z., et al. (2020a). Long Noncoding RNA A2M-AS1 Promotes Breast Cancer Progression by Sponging 
microRNA-146b to Upregulate MUC19. Int. J. Gen. Med. 13, 1305-1316. doi:10.2147/IJGM.S278564

Liu, Y. R., Cai, Q. Y., Gao, Y. G., Luan, X., Guan, Y. Y., Lu, Q., et al. (2018b). Alantolactone, a Sesquiterpene Lactone, Inhibits Breast Cancer Growth by Antiangiogenic Activity via Blocking VEGFR2 Signaling. Phytother Res. 32 (4), 643-650. doi:10.1002/ptr.6004

Liu, Z., Xiang, C., Han, M., Meng, N., Luo, J., and Fu, R. (2020b). Study on Tim3 Regulation of Multiple Myeloma Cell Proliferation via NF-Kb Signal Pathways. Front. Oncol. 10, 584530. doi:10.3389/fonc.2020.584530

Low, H. B., and Zhang, Y. (2016). Regulatory Roles of MAPK Phosphatases in Cancer. Immune Netw. 16 (2), 85-98. doi:10.4110/in.2016.16.2.85

Martínez-Limón, A., Joaquin, M., Caballero, M., Posas, F., and de Nadal, E. (2020). The P38 Pathway: From Biology to Cancer Therapy. Int. J. Mol. Sci. 21 (6), 1913. doi:10.3390/ijms21061913

Maryam, A., Mehmood, T., Zhang, H., Li, Y., Khan, M., and Ma, T. (2017). Alantolactone Induces Apoptosis, Promotes STAT3 Glutathionylation and Enhances Chemosensitivity of A549 Lung Adenocarcinoma Cells to Doxorubicin via Oxidative Stress. Sci. Rep. 7 (1), 6242. doi:10.1038/s41598017-06535-y

Mi, X. G., Song, Z. B., Wu, P., Zhang, Y. W., Sun, L. G., Bao, Y. L., et al. (2014). Alantolactone Induces Cell Apoptosis Partially through Down-Regulation of Testes-specific Protease 50 Expression. Toxicol. Lett. 224 (3), 349-355. doi:10.1016/j.toxlet.2013.11.002

Moore, A., and Donahue, T. (2019). Pancreatic Cancer. JAMA 322 (14), 1426. doi:10.1001/jama.2019.14699

Nadda, R. K., Ali, A., Goyal, R. C., Khosla, P. K., and Goyal, R. (2020). Aucklandia costus (Syn. Saussurea costus): Ethnopharmacology of an Endangered Medicinal Plant of the Himalayan Region. J. Ethnopharmacol 263, 113199. doi:10.1016/j.jep.2020.113199

Nakatani, K., Maehama, T., Nishio, M., Otani, J., Yamaguchi, K., Fukumoto, M., et al. (2021). Alantolactone Is a Natural Product that Potently Inhibits YAP1/ TAZ through Promotion of Reactive Oxygen Species Accumulation. Cancer Sci. 112 (10), 4303-4316. doi:10.1111/cas.15079

Neoptolemos, J. P., Kleeff, J., Michl, P., Costello, E., Greenhalf, W., and Palmer, D. H. (2018). Therapeutic Developments in Pancreatic Cancer: Current and Future Perspectives. Nat. Rev. Gastroenterol. Hepatol. 15 (6), 333-348. doi:10.1038/s41575-018-0005-x

Nordlund, J., and Syvänen, A. C. (2018). Epigenetics in Pediatric Acute Lymphoblastic Leukemia. Semin. Cancer Biol. 51, 129-138. doi:10.1016/ j.semcancer.2017.09.001

Pal, H. C., Sehar, I., Bhushan, S., Gupta, B. D., and Saxena, A. K. (2010). Activation of Caspases and Poly (ADP-Ribose) Polymerase Cleavage to Induce Apoptosis in Leukemia HL-60 Cells by Inula Racemosa. Toxicol. Vitro 24 (6), 1599-1609. doi:10.1016/j.tiv.2010.06.007

Pei, W., Huang, X., Ni, B., Zhang, R., Niu, G., and You, H. (2021). Selective STAT3 Inhibitor Alantolactone Ameliorates Osteoarthritis via Regulating Chondrocyte Autophagy and Cartilage Homeostasis. Front. Pharmacol. 12, 730312. doi:10.3389/fphar.2021.730312

Petrowsky, H., Fritsch, R., Guckenberger, M., De Oliveira, M. L., Dutkowski, P., and Clavien, P. A. (2020). Modern Therapeutic Approaches for the Treatment of Malignant Liver Tumours. Nat. Rev. Gastroenterol. Hepatol. 17 (12), 755-772. doi:10.1038/s41575-020-0314-8

Ranjkesh, M., Hajibonabi, F., Seifar, F., Tarzamni, M. K., Moradi, B., and Khamnian, Z. (2020). Diagnostic Value of Elastography, Strain Ratio, and Elasticity to B-Mode Ratio and Color Doppler Ultrasonography in Breast Lesions. Int. J. Gen. Med. 13, 215-224. doi:10.2147/IJGM.S247980

Reger de Moura, C., Prunotto, M., Sohail, A., Battistella, M., Jouenne, F., Marbach, D., et al. (2020). Discoidin Domain Receptors in Melanoma: Potential Therapeutic Targets to Overcome MAPK Inhibitor Resistance. Front. Oncol. 10, 1748. doi:10.3389/fonc.2020.01748

Ren, Y., Lv, C., Zhang, J., Zhang, B., Yue, B., Luo, X., et al. (2021). Alantolactone Exhibits Antiproliferative and Apoptosis-Promoting Properties in colon Cancer Model via Activation of the MAPK-JNK/c-Jun Signaling Pathway. Mol. Cel Biochem 476 (12), 4387-4403. doi:10.1007/s11010-021-04247-6

Ruan, S., Shi, N., Chen, Z., Han, H., Wang, H., Jin, L., et al. (2020). The Role of Hyperthermic Intraperitoneal Chemotherapy in the Treatment of Spontaneously Ruptured Hepatocellular Carcinoma: a Pilot Study. Ann. Transl Med. 8 (18), 1132. doi:10.21037/atm-20-5829
Seo, J. Y., Park, J., Kim, H. J., Lee, I. A., Lim, J. S., Lim, S. S., et al. (2009). Isoalantolactone from Inula Helenium Caused Nrf2-Mediated Induction of Detoxifying Enzymes. J. Med. Food 12 (5), 1038-1045. doi:10.1089/ jmf.2009.0072

Shen, S., Yan, Z., Wu, J., Liu, X., Guan, G., Zou, C., et al. (2020). Characterization of ROS Metabolic Equilibrium Reclassifies Pan-Cancer Samples and Guides Pathway Targeting Therapy. Front. Oncol. 10, 581197. doi:10.3389/ fonc.2020.581197

Shi, C., Lan, W., Wang, Z., Yang, D., Wei, J., Liu, Z., et al. (2020). Alantolactone Inhibits Cell Autophagy and Promotes Apoptosis via AP2M1 in Acute Lymphoblastic Leukemia. Cancer Cel Int 20, 442. doi:10.1186/s12935-020-01537-9

Shi, Y., Bao, Y. L., Wu, Y., Yu, C. L., Huang, Y. X., Sun, Y., et al. (2011). Alantolactone Inhibits Cell Proliferation by Interrupting the Interaction between Cripto-1 and Activin Receptor Type II A in Activin Signaling Pathway. J. Biomol. Screen. 16 (5), 525-535. doi:10.1177/1087057111398486

Suliman, M. S., Singh, M., Ajmeri, A. N., Stuart, D. L., and Teka, S. T. (2019). Virchow's Node: a Case Report of an Extremely Rare Presentation of Metastasis of Adenocarcinoma with Mucinous Features from the colon. Int. J. Gen. Med. 12, 137-140. doi:10.2147/IJGM.S201617

Sun, X., Xu, H., Dai, T., Xie, L., Zhao, Q., Hao, X., et al. (2021). Alantolactone Inhibits Cervical Cancer Progression by Downregulating BMI1. Sci. Rep. 11 (1), 9251. doi:10.1038/s41598-021-87781-z

Taniguchi, K., and Karin, M. (2018). NF- $\mathrm{kB}$, Inflammation, Immunity and Cancer: Coming of Age. Nat. Rev. Immunol. 18 (5), 309-324. doi:10.1038/nri.2017.142

Tavares, W. R., and Seca, A. M. L. (2019). Inula L. Secondary Metabolites against Oxidative Stress-Related Human Diseases. Antioxidants (Basel) 8 (5), 122. doi:10.3390/antiox 8050122

The Lancet Gastroenterology Hepatology, H. (2018). Colorectal Cancer Screening: Is Earlier Better. Lancet Gastroenterol. Hepatol. 3 (8), 519. doi:10.1016/S24681253(18)30205-X

The Lancet Oncology, O. (2017). Colorectal Cancer: a Disease of the Young. Lancet Oncol. 18 (4), 413. doi:10.1016/S1470-2045(17)30202-4

Tubío-Pérez, R. A., Torres-Durán, M., Pérez-Ríos, M., Fernández-Villar, A., and Ruano-Raviña, A. (2020). Lung Emphysema and Lung Cancer: what Do We Know about it. Ann. Transl Med. 8 (21), 1471. doi:10.21037/atm-20-1180

Wan, X., Zhang, H., Zhang, Y., and Peng, Y. (2020). Metastases to the Breast from Extramammary Nonhematological Malignancies: Case Series. Int. J. Gen. Med. 13, 1105-1114. doi:10.2147/IJGM.S276602

Wang, H., Zhang, S., Song, L., Qu, M., and Zou, Z. (2020). Synergistic Lethality between PARP-Trapping and Alantolactone-Induced Oxidative DNA Damage in Homologous Recombination-Proficient Cancer Cells. Oncogene 39 (14), 2905-2920. doi:10.1038/s41388-020-1191-x

Wang, J., Zhang, Y., Liu, X., Wang, J., Li, B., Liu, Y., et al. (2019a). Alantolactone Enhances Gemcitabine Sensitivity of Lung Cancer Cells through the Reactive Oxygen Species-Mediated Endoplasmic Reticulum Stress and Akt/GSK3 $\beta$ Pathway. Int. J. Mol. Med. 44 (3), 1026-1038. doi:10.3892/ijmm.2019.4268

Wang, K., Gong, Q., Zhan, Y., Chen, B., Yin, T., Lu, Y., et al. (2019b). Blockage of Autophagic Flux and Induction of Mitochondria Fragmentation by Paroxetine Hydrochloride in Lung Cancer Cells Promotes Apoptosis via the ROS-MAPK Pathway. Front Cel Dev Biol 7, 397. doi:10.3389/fcell.2019.00397

Wang, X., Yu, Z., Wang, C., Cheng, W., Tian, X., Huo, X., et al. (2017). Alantolactone, a Natural Sesquiterpene Lactone, Has Potent Antitumor Activity against Glioblastoma by Targeting IKK $\beta$ Kinase Activity and Interrupting NF-Kb/cox-2-Mediated Signaling Cascades. J. Exp. Clin. Cancer Res. 36 (1), 93. doi:10.1186/s13046-017-0563-8

Wang, X., Zou, S., Ren, T., Zhao, L.-J., Yu, L.-F., Li, X.-Y., et al. (2021a). Alantolactone Suppresses the Metastatic Phenotype and Induces the Apoptosis of Glioblastoma Cells by Targeting LIMK Kinase Activity and Activating the cofilin/Gactin Signaling cascade. Int. J. Mol. Med. 47 (5), 68. doi:10.3892/ijmm.2021.4901

Wang, Z., Hu, Q., Chen, H., Shi, L., He, M., Liu, H., et al. (2021b). Inhibition of Growth of Esophageal Cancer by Alantolactone via Wnt/ $\beta$ Catenin Signaling. Acamc. doi:10.2174/1871520621666210112124546

Wei, W., Huang, H., Zhao, S., Liu, W., Liu, C. X., Chen, L., et al. (2013). Alantolactone Induces Apoptosis in Chronic Myelogenous Leukemia Sensitive or Resistant to Imatinib through NF-Kb Inhibition and Bcr/Abl Protein Deletion. Apoptosis 18 (9), 1060-1070. doi:10.1007/s10495-0130854-2 
Wirth, M., and Schneider, G. (2016). MYC: A Stratification Marker for Pancreatic Cancer Therapy. Trends Cancer 2 (1), 1-3. doi:10.1016/j.trecan.2015.12.002

Wu, G., Zhao, Z., Yan, Y., Zhou, Y., Wei, J., Chen, X., et al. (2020). CPS1 Expression and its Prognostic Significance in Lung Adenocarcinoma. Ann. Transl Med. 8 (6), 341. doi:10.21037/atm.2020.02.146

Xu, L., Dong, Q., Long, Y., Tang, X., Zhang, N., and Lu, K. (2020). Dynamic Changes of Blood Lipids in Breast Cancer Patients after (Neo)adjuvant Chemotherapy: A Retrospective Observational Study. Int. J. Gen. Med. 13, 817-823. doi:10.2147/IJGM.S273056

Xu, R., Peng, Y., Wang, M., and Li, X. (2019a). Intestinal Absorption of Isoalantolactone and Alantolactone, Two Sesquiterpene Lactones from Radix Inulae, Using Caco-2 Cells. Eur. J. Drug Metab. Pharmacokinet. 44 (2), 295-303. doi:10.1007/s13318-018-0510-x

Xu, R., Zhou, G., Peng, Y., Wang, M., and Li, X. (2015). Pharmacokinetics, Tissue Distribution and Excretion of Isoalantolactone and Alantolactone in Rats after Oral Administration of Radix Inulae Extract. Molecules 20 (5), 7719-7736. doi:10.3390/molecules20057719

Xu, X., Huang, L., Zhang, Z., Tong, J., Mi, J., Wu, Y., et al. (2019b). Targeting Nononcogene ROS Pathway by Alantolactone in B Cell Acute Lymphoblastic Leukemia Cells. Life Sci. 227, 153-165. doi:10.1016/j.lfs.2019.04.034

Yan, Y. Y., Zhang, Q., Zhang, B., Yang, B., and Lin, N. M. (2020). Active Ingredients of Inula Helenium L. Exhibits Similar Anti-cancer Effects as Isoalantolactone in Pancreatic Cancer Cells. Nat. Prod. Res. 34 (17), 2539-2544. doi:10.1080/ 14786419.2018 .1543676

Yang, R., Zhou, Y., Wang, Y., Du, C., and Wu, Y. (2020). Trends in Cancer Incidence and Mortality Rates in the United States from 1975 to 2016. Ann. Transl Med. 8 (24), 1671. doi:10.21037/atm-20-7841

Yao, D., Li, Z., Huo, C., Wang, Y., Wu, Y., Zhang, M., et al. (2016). Identification of In Vitro and In Vivo Metabolites of Alantolactone by UPLC-TOF-MS/MS. J. Chromatogr. B Analyt Technol. Biomed. Life Sci. 1033-1034, 250-260. doi:10.1016/j.jchromb.2016.08.034

Yao, Y., Xia, D., Bian, Y., Sun, Y., Zhu, F., Pan, B., et al. (2015). Alantolactone Induces G1 Phase Arrest and Apoptosis of Multiple Myeloma Cells and Overcomes Bortezomib Resistance. Apoptosis 20 (8), 1122-1133. doi:10.1007/s10495-015-1140-2

Yin, C., Dai, X., Huang, X., Zhu, W., Chen, X., Zhou, Q., et al. (2019). Alantolactone Promotes ER Stress-Mediated Apoptosis by Inhibition of TrxR1 in TripleNegative Breast Cancer Cell Lines and in a Mouse Model. J. Cel Mol Med 23 (3), 2194-2206. doi:10.1111/jcmm.14139

Zhang, J., Li, Y., Duan, D., Yao, J., Gao, K., and Fang, J. (2016a). Inhibition of Thioredoxin Reductase by Alantolactone Prompts Oxidative Stress-Mediated Apoptosis of HeLa Cells. Biochem. Pharmacol. 102, 34-44. doi:10.1016/ j.bcp.2015.12.004

Zhang, J., Shen, L., Li, X., Song, W., Liu, Y., and Huang, L. (2019a). Nanoformulated Codelivery of Quercetin and Alantolactone Promotes an Antitumor Response through Synergistic Immunogenic Cell Death for Microsatellite-Stable Colorectal Cancer. ACS Nano 13 (11), 12511-12524. doi:10.1021/acsnano.9b02875

Zhang, J. P., Xu, X. K., Ye, J., Yang, Y. X., Gao, S., Li, H. L., et al. (2016b). Three New Sesquiterpene Lactone Dimers from Carpesium Macrocephalum. Fitoterapia 110, 72-76. doi:10.1016/j.fitote.2016.02.013

Zhang, R., Chen, J., Jiang, Y., Wang, J., and Chen, S. (2020a). Prognostic Nomogram for Hepatocellular Carcinoma with Fibrosis of Varying Degrees: a Retrospective Cohort Study. Ann. Transl Med. 8 (21), 1429. doi:10.21037/atm20-3267
Zhang, R., Li, Y., Yu, H., Liu, L., Zhu, C., Zuo, S., et al. (2020b). An Aberrant DNA Methylation Signature for Predicting Hepatocellular Carcinoma. Ann. Transl Med. 8 (24), 1667. doi:10.21037/atm-20-7804

Zhang, X., and Zhang, H. M. (2019). Alantolactone Induces Gastric Cancer BGC823 Cell Apoptosis by Regulating Reactive Oxygen Species Generation and the AKT Signaling Pathway. Oncol. Lett. 17 (6), 4795-4802. doi:10.3892/ ol.2019.10172

Zhang, Y., Bao, Y. L., Wu, Y., Yu, C. L., Huang, Y. X., Sun, Y., et al. (2013). Alantolactone Induces Apoptosis in RKO Cells through the Generation of Reactive Oxygen Species and the Mitochondrial Pathway. Mol. Med. Rep. 8 (4), 967-972. doi:10.3892/mmr.2013.1640

Zhang, Y., Weng, Q., Han, J., and Chen, J. (2020c). Alantolactone Suppresses Human Osteosarcoma through the PI3K/AKT Signaling Pathway. Mol. Med. Rep. 21 (2), 675-684. doi:10.3892/mmr.2019.10882

Zhang, Y., Zhao, Y., Ran, Y., Guo, J., Cui, H., and Liu, S. (2019b). Alantolactone Exhibits Selective Antitumor Effects in HELA Human Cervical Cancer Cells by Inhibiting Cell Migration and Invasion, G2/M Cell Cycle Arrest, Mitochondrial Mediated Apoptosis and Targeting Nf-kB Signalling Pathway. J. BUON 24 (6), 2310-2315.

Zhao, P., Pan, Z., Luo, Y., Zhang, L., Li, X., Zhang, G., et al. (2015). Alantolactone Induces Apoptosis and Cell Cycle Arrest on Lung Squamous Cancer SK-MES-1 Cells. J. Biochem. Mol. Toxicol. 29 (5), 199-206. doi:10.1002/jbt.21685

Zheng, H., Yang, L., Kang, Y., Chen, M., Lin, S., Xiang, Y., et al. (2019). Alantolactone Sensitizes Human Pancreatic Cancer Cells to EGFR Inhibitors through the Inhibition of STAT3 Signaling. Mol. Carcinog 58 (4), 565-576. doi:10.1002/mc.22951

Zhou, B., Ye, J., Yang, N., Chen, L., Zhuo, Z., Mao, L., et al. (2018). Metabolism and Pharmacokinetics of Alantolactone and Isoalantolactone in Rats: Thiol Conjugation as a Potential Metabolic Pathway. J. Chromatogr. B Analyt Technol. Biomed. Life Sci. 1072, 370-378. doi:10.1016/ j.jchromb.2017.11.039

Zhou, Z., Ni, K., Deng, H., and Chen, X. (2020). Dancing with Reactive Oxygen Species Generation and Elimination in Nanotheranostics for Disease Treatment. Adv. Drug Deliv. Rev. 158, 73-90. doi:10.1016/j.addr.2020.06.006 Zimmermann, M., Zimmermann-Kogadeeva, M., Wegmann, R., and Goodman, A. L. (2019). Mapping Human Microbiome Drug Metabolism by Gut Bacteria and Their Genes. Nature 570 (7762), 462-467. doi:10.1038/s41586-019-1291-3

Conflict of Interest: The authors declare that the research was conducted in the absence of any commercial or financial relationships that could be construed as a potential conflict of interest.

Publisher's Note: All claims expressed in this article are solely those of the authors and do not necessarily represent those of their affiliated organizations, or those of the publisher, the editors and the reviewers. Any product that may be evaluated in this article, or claim that may be made by its manufacturer, is not guaranteed or endorsed by the publisher.

Copyright $\odot 2021$ Cai, Gao, Peng, Xu, Peng, Li, Chen, Zeng, Hu and Yan. This is an open-access article distributed under the terms of the Creative Commons Attribution License (CC BY). The use, distribution or reproduction in other forums is permitted, provided the original author $(s)$ and the copyright owner(s) are credited and that the original publication in this journal is cited, in accordance with accepted academic practice. No use, distribution or reproduction is permitted which does not comply with these terms. 